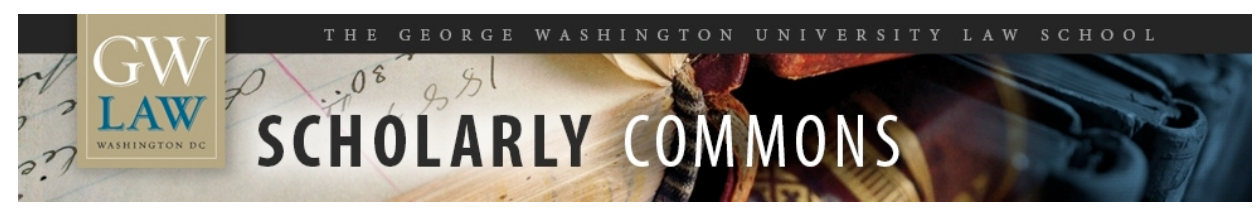

GW Law Faculty Publications \& Other Works

Faculty Scholarship

2011

\title{
Environmental Protection and Human Rights
}

Dinah L. Shelton

George Washington University Law School, dshelton@law.gwu.edu

Donald K. Anton

Follow this and additional works at: https://scholarship.law.gwu.edu/faculty_publications

Part of the Law Commons

\section{Recommended Citation}

Donald K. Anton \& Dinah L. Shelton, Environmental Protection and Human Rights (2011).

This Book Part is brought to you for free and open access by the Faculty Scholarship at Scholarly Commons. It has been accepted for inclusion in GW Law Faculty Publications \& Other Works by an authorized administrator of Scholarly Commons. For more information, please contact spagel@law.gwu.edu. 


\section{Environmental Protection and Human Rights}

Donald K. Anton

Australia National University

College of Law
Dinah L. Shelton

George Washington University

School of Law 


\section{Introduction}

Environmental protection emerged as a general public concern in the 1960 , although laws to counter specific local problems like urban air pollution can be found as early as the fourteenth century, when Edward I prohibited the burning of coal in open furnaces in London. More recently, as knowledge has spread about transboundary and global environmental problems, the public has begun seeking widespread preventive and remedial action to ensure that natural conditions remain conducive to life and to human well-being.

Policy makers responding to these demands increasingly understand that environmental protection must be addressed in a holistic and expansive manner. Local problems cannot be separated from national, regional, or even global conditions. As a result, the interface of domestic (both national and local) and international environmental law has rapidly expanded. Such an evolution corresponds to the physical reality of a biosphere composed of interdependent elements that do not recognize political boundaries and the increasingly transnational character of the human activities that harm nature and its processes. Internationalization of markets and the emergence of a global civil society present new opportunities as well as new challenges. Communication networks make possible more rapid knowledge of the existence and scope of environmental problems, but the widespread movement of persons and products may also contribute to those problems, for example, through the introduction of alien species and the spread of pollutants. Overconsumption threatens to exhaust living and nonliving resources, whereas rising greenhouse gas emissions detrimentally modify the global climate. Population concentrations strain resources and create levels of pollution beyond the earth's assimilative capacity. New problems resulting from technology and changes in the nature or scope of human activities are constantly being identified, such as the introduction of unprocessed endocrine-disrupting pharmaceuticals into fresh water. As a consequence, there is a conistant need to develop and revise the national and international legal framework.

The geographic scope of environmental law is global, but so are its interdisciplinary requirements. Beyond such obvious topics as water law and endangered species legislation, laws and policies concerning energy, trade, investment, transportation, and consumer protection also affect environmental conditions. At the center of the problems, impacts, and solutions are individuals with rights guaranteed by national and international law. The interface between human rights and the environment is the focus of this book.

The first chapter introduces the problems posed, that is, the environmental stresses that threaten present and future populations throughout the world and the anthropogenic origins of those stresses. The chapter then turns to the various legal approaches that are often used to prevent and remedy environmental degradation, from property law concepts of nuisance 
and public trust to rights-based approaches. The chapter also provides a brief introduction to international environmental law and its sources.

\section{A. Defining the Environment and Its Characteristics}

A legal definition of the environment serves to delineate the scope of the subject, to determine the application of legal rules, and to establish the extent of liability when harm occurs. The word environment is borrowed from the French word environner, which means "to encircle." It applies broadly to all that surrounds a central point; thus, environment can include the aggregate of natural, social, and cultural conditions that influence the life of an individual or community. As such, environmental problems can be deemed to include such problems as traffic congestion, crime, noise, and poverty. Geographically, environment can refer to a limited area or encompass the entire planet, including the atmosphere and stratosphere. Consider the scope of the following definitions:

"Environment": a complex of natural and anthropogenic factors and elements that are mutually interrelated and affect the ecological equilibrium and the quality of life, human health, the cultural and historical heritage and the landscape.

Sec. 1(1) Environmental Protection Act (Supp.) (1991), Bulgaria

"Environment": that part of nature which is or could be influenced by human activity.

Art. 5(1) (1), Environmental Protection Act of June 1993, Slovenia

\section{"Environment" includes}

- natural resources both biotic and abiotic, such as air, water, soil, fauna and flora and the interactions between the same factors;

- property which forms part of the cultural heritage;

- the characteristics aspects of landscape.

Art. 2(1), Convention on Civil Liability for Damage Resulting from Activities Dangerous to the Environment (Lugano, June 21, 1993)

The sum of all external conditions affecting the life, development and survival of an organism.

U.S. Environmental Protection Agency, www.epa.gov/OCEPAterm, CERCLA, 42 U.S. Code ch. 103, $\int 101(8)$

The definitions encompass and reflect realities that shape environmental policy and law. First, environmental protection measures must take into account the laws of nature. The science of ecology recognizes that all environmental milieu (air, water, soil) and all species are interdependent. Harm to one aspect of the environment is thus likely to have broad and unforeseen consequences on other dimensions of nature, including human well-being. A toxic chemical spill at a gold mine, for example, not only will pollute the nearby soil but also can enter streams and rivers, be transported to the sea, and enter the food chain through absorption by plants and animals. Another reality is that many degraded or exploited resources are nonrenewable and thus exhaustible; even living resources may become extinct. Substances that in isolation may be benign can combine with others to produce new and unforeseen harms.

Planning and regulation is made more difficult by scientific uncertainty about many aspects of the physical world. Although there is an unprecedented amount of knowledge 
today, no one knows the ecological processes over the 5-billion-year history of the earth with sufficient detail and understanding to be able to predict all the consequences and causal relationships of various human activities. Scientific uncertainty thus often attends issues of the nature and scope of adverse environmental impacts of human activities. Exacerbating the uncertainty, damage often is perceived only years after the causative actions occur. It becomes difficult to determine future risk and to develop appropriate policies to avoid long-term harm. Debate centers on whether to adopt policies that assume that harmful consequences will occur unless activities are proven safe or whether to take a less cautious approach, knowing that some environmental consequences will be irreversible and may be life threatening.

All human activities have an impact on the environment. Each individual has an "ecological footprint" that represents the sum of that person's resource use and contributions to pollution. The ecological footprints of individuals vary considerably both within states and from one region of the world to another. Taken together, however, these impacts mean that environmental degradation generally stems from one of two main causes:

1. Use of resources at unsustainable levels

2. Contamination of the environment through pollution and waste at levels beyond the capacity of the environment to absorb them or render them harmless

These realities make it difficult to establish the limits of environmental law as an independent legal field; indeed, they imply the integration of environmental protection into all areas of law and policy.

\title{
Questions and Discussion
}

1. Under each of the foregoing definitions, what range of consequences would a proponent have to evaluate in a legally required environmental impact assessment prior to damming a river for hydroelectric power or creating a public park?

2. Do the definitions reflect an emphasis on human well-being, or are they seeking to protect nature independently of its utility to humans? Would environmental law include human rights issues under these definitions?

\section{B. State of the Planet}

\author{
Millennium Ecosystem Assessment \\ Ecosystems and Human Well-Being: Synthesis \\ 1, 9-15, 17-18, 20-22, 23-24 (World Resources Inst., 2005) \\ (footnotes, figures and tables omitted)
}

The U.N. secretary-general Kofi Annan called for preparation of the Millennium Ecosystem Assessment (MA) in 2000 in his report to the U.N. General Assembly, We the Peoples: The Role of the United Nations in the 21st Century. With the support of member states, the United Nations initiated the MA in 2001, with the secretariat coordinated by the United Nations Environment Programme. A governing board included representatives of international institutions, governments, business, nongovernmental organizations (NGOs), and indigenous peoples; the work ultimately involved more than 1,360 experts worldwide. The objective of the MA was to assess the consequences of ecosystem change for human well-being and to establish the scientific basis for actions 
needed to enhance the conservation and sustainable use of ecosystems and their contributions to human well-being. The MA findings are contained in five technical volumes and six synthesis reports on the world's ecosystems and the services they provide. The following extract is from one of the synthesis reports. $-E d s$.]

...An ecosystem is a dynamic complex of plant, animal, and microorganism communities and the nonliving environment interacting as a functional unit... Ecosystem services are the benefits people obtain from ecosystems. These include provisioning services such as food, water, timber, and fiber; regulating services that affect climate, floods, disease, wastes, and water quality; cultural services that provide recreational, aesthetic, and spiritual benefits; and supporting services such as soil formation, photosynthesis, and nutrient cycling... Although the MA emphasizes the linkages between ecosystems and human well-being, it recognizes that the actions people take that influence ecosystems result not just from concern about human well-being but also from considerations of the intrinsic value of species and ecosystems. Intrinsic value is the value of something in and for itself, irrespective of its utility for someone else.

Everyone in the world depends completely on Earth's ecosystems and the services they provide, such as food, water, disease management, climate regulation, spiritual fulfillment, and aesthetic enjoyment. Over the past 50 years, humans have changed these ecosystems more rapidly and extensively than in any comparable period of time in human history, largely to meet rapidly growing demands for food, fresh water, timber, fiber, and fuel. This transformation of the planet has contributed to substantial net gains in human well-being and economic development. But not all regions and groups of people have benefited from this process - in fact, many have been harmed. Moreover, the full costs associated with these gains are only now becoming apparent....

\section{Finding \#1: [Ecosystem Change in the Last 50 Years]}

The structure and functioning of the world's ecosystems changed more rapidly in the second half of the twentieth century than at any time in human history.

- More land was converted to cropland in the 30 years after 1950 than in the 150 years between 1700 and 1850 . Cultivated systems (areas where at least $30 \%$ of the landscape is in croplands, shifting cultivation, confined livestock production, or freshwater aquaculture) now cover one quarter of Earth's terrestrial surface.

- Approximately $20 \%$ of the world's coral reefs were lost and an additional $20 \%$ degraded in the last several decades of the twentieth century, and approximately $35 \%$ of mangrove area was lost during this time (in countries for which sufficient data exist, which encompass about half of the area of mangroves).

- The amount of water impounded behind dams quadrupled since 1960 , and three to six times as much water is held in reservoirs as in natural rivers. Water withdrawals from rivers and lakes doubled since 1960 ; most water use ( $70 \%$ worldwide) is for agriculture.

- Since 1960 , flows of reactive (biologically available) nitrogen in terrestrial ecosystems have doubled, and flows of phosphorus have tripled. More than half of all the synthetic nitrogen fertilizer, which was first manufactured in 1913, ever used on the planet has been used since 1985.

- Since 1750 , the atmospheric concentration of carbon dioxide has increased by about $32 \%$ (from about 280 to 376 parts per million in 2003 ), primarily due to the combustion of fossil fuels and land use changes. Approximately $60 \%$ of that increase ( 60 parts per million) has taken place since 1959 . 
Humans are fundamentally, and to a significant extent irreversibly, changing the diversity of life on Earth, and most of these changes represent a loss of biodiversity.

- More than two thirds of the area of 2 of the world's 14 major terrestrial biomes and more than half of the area of 4 other biomes had been converted by 1990 , primarily to agriculture. ${ }^{1}$

- Across a range of taxonomic groups, either the population size or range or both of the majority of species is currently declining.

- The distribution of species on Earth is becoming more homogenous; in other words, the set of species in any one region of the world is becoming more similar to the set in other regions primarily as a result of introductions of species, both intentionally and inadvertently in association with increased travel and shipping.

- The number of species on the planet is declining. Over the past few hundred years, humans have increased the species extinction rate by as much as 1,00o times over background rates typical over the planet's history (medium certainty). Some 10-30\% of mammal, bird, and amphibian species are currently threatened with extinction (medium to high certainty). Freshwater ecosystems tend to have the highest proportion of species threatened with extinction.

- Genetic diversity has declined globally, particularly among cultivated species.

Most changes to ecosystems have been made to meet a dramatic growth in the demand for food, water, timber, fiber, and fuel.

Some ecosystem changes have been the inadvertent result of activities unrelated to the use of ecosystem services, such as the construction of roads, ports, and cities and the discharge of pollutants. But most ecosystem changes were the direct or indirect result of changes made to meet growing demands for ecosystem services, and in particular growing demands for food, water, timber, fiber, and fuel (fuelwood and hydropower).

Between 1960 and 2000 , the demand for ecosystem services grew significantly as world population doubled to 6 billion people and the global economy increased more than sixfold. To meet this demand, food production increased by roughly two and a half times, water use doubled, wood harvests for pulp and paper production tripled, installed hydropower capacity doubled, and timber production increased by more than half.

The growing demand for these ecosystem services was met both by consuming an increasing fraction of the available supply (for example, diverting more water for irrigation or capturing more fish from the sea) and by raising the production of some services, such as crops and livestock. The latter has been accomplished through the use of new technologies (such as new crop varieties, fertilization, and irrigation) as well as through increasing the area managed for the services in the case of crop and livestock production and aquaculture.

\section{Finding \#2: [Gains and Losses from Ecosystem Change]}

\section{Degradation and Unsustainable Úse of Ecosystem Services}

Approximately $60 \%$ ( 15 out of 24 ) of the ecosystem services evaluated in this assessment (including $70 \%$ of regulating and cultural services) are being degraded or used unsustainably.... Ecosystem services that have been degraded over the past 50 years include capture fisheries, water supply, waste treatment and detoxification, water purification, natural hazard

1 [A biome is the largest unit of ecological classification recognized below the level of the entire globe. It includes such groupings as deserts, tundra, temperate broadleaf forests, and flooded grasslands and savannas. Considerable ecological data have been reported and modeling undertaken using this categorization, making it a convenient basis for assessment. - Eds.] 
protection, regulation of air quality, regulation of regional and local climate, regulation of erosion, spiritual fulfillment, and aesthetic enjoyment. The use of two ecosystem services - capture fisheries and fresh water - is now well beyond levels that can be sustained even at current demands, much less future ones. At least one quarter of important commercial fish stocks are overharvested (high certainty). From $5 \%$ to possibly $25 \%$ of global freshwater use exceeds long-term accessible supplies and is now met either through engineered water transfers or overdraft of groundwater supplies (low to medium certainty).... Some 15-35\% of irrigation withdrawals exceed supply rates and are therefore unsustainable (low to medium certainty). While 15 services have been degraded, only 4 have been enhanced in the past 50 years, three of which involve food production: crops, livestock, and aquaculture. Terrestrial ecosystems were on average a net source of $\mathrm{CO}_{2}$ emissions during the nineteenth and early twentieth centuries, but became a net sink around the middle of the last century, and thus in the last 50 years the role of ecosystems in regulating global climate through carbon sequestration has also been enhanced.

Actions to increase one ecosystem service often cause the degradation of other services. For example, because actions to increase food production typically involve increased use of water and fertilizers or expansion of the area of cultivated land, these same actions often degrade other ecosystem services, including reducing the availability of water for other uses, degrading water quality, reducing biodiversity, and decreasing forest cover (which in turn may lead to the loss of forest products and the release of greenhouse gasses). Similarly, the conversion of forest to agriculture can significantly change the frequency and magnitude of floods, although the nature of this impact depends on the characteristics of the local ecosystem and the type of land cover change....

- Most resource management decisions are most strongly influenced by ecosystem services entering markets; as a result, the nonmarketed benefits are often lost or degraded. These nonmarketed benefits are often high and sometimes more valuable than the marketed ones. For example, one of the most comprehensive studies to date, which examined the marketed and nonmarketed economic values associated with forests in eight Mediterranean countries, found that timber and fuelwood generally accounted for less than a third of total economic value of forests in each country. Values associated with non-wood forest products, recreation, hunting, watershed protection, carbon sequestration, and passive use (values independent of direct uses) accounted for between $25 \%$ and $96 \%$ of the total economic value of the forests.

- The total economic value associated with managing ecosystems more sustainably is often higher than the value associated with the conversion of the ecosystem through farming, clear-cut logging, or other intensive uses. Relatively few studies have compared the total economic value (including values of both marketed and nonmarketed ecosystem services) of ecosystems under alternate management regimes, but some of the studies that do exist have found that the benefit of managing the ecosystem more sustainably exceeded that of converting the ecosystem.

- The economic and public health costs associated with damage to ecosystem services can be substantial.

- The early 1990 collapse of the Newfoundland cod fishery due to overfishing resulted in the loss of tens of thousands of jobs and cost at least $\$ 2$ billion in income support and retraining.

- In 1996, the cost of U.K. agriculture resulting from the damage that agricultural practices cause to water (pollution and eutrophication, a process whereby excessive plant growth depletes oxygen in the water), air (emissions of greenhouse gases), soil (off-site erosion damage, emissions of greenhouse gases), and biodiversity was $\$ 2.6$ billion, or $9 \%$ of average yearly gross farm receipts for the 1990s. Similarly, the damage costs of freshwater eutrophication alone in England and Wales (involving factors including reduced value of waterfront dwellings, water treatment costs, reduced recreational value of water bodies, and tourism 
losses) was estimated to be $\$ 105$ [million]-\$160 million per year in the 1990s, with an additional $\$ 77$ million a year being spent to address those damages.

- The incidence of diseases of marine organisms and the emergence of new pathogens is increasing, and some of these, such as ciguatera, harm human health. Episodes of harmful (including toxic) algal blooms in coastal waters are increasing in frequency and intensity, harming other marine resources such as fisheries as well as human health. In a particularly severe outbreak in Italy in 1989, harmful algal blooms cost the coastal aquaculture industry $\$ 10$ million and the Italian tourism industry $\$ 11.4$ million.

- The frequency and impact of floods and fires has increased significantly in the past 50 years, in part due to ecosystem changes. Examples are the increased susceptibility of coastal populations to tropical storms when mangrove forests are cleared and the increase in downstream flooding that followed land use changes in the upper Yangtze River. Annual economic losses from extreme events increased tenfold from the 1950 s to approximately $\$ 70$ billion in 2003 , of which natural catastrophes (floods, fires, storms, drought, earthquakes) accounted for $84 \%$ of insured losses.

- The impact of the loss of cultural services is particularly difficult to measure, but it is especially important for many people. Human cultures, knowledge systems, religions, and social interactions have been strongly influenced by ecosystems. A number of the MA sub-global assessments found that spiritual and cultural values of ecosystems were as important as other services for many local communities, both in developing countries (the importance of sacred groves of forest in India, for example) and industrial ones (the importance of urban parks, for instance).

The degradation of ecosystem services represents loss of a capital asset. Both renewable resources such as ecosystem services and nonrenewable resources such as mineral deposits, some soil nutrients, and fossil fuels are capital assets. Yet traditional national accounts do not include measures of resource depletion or of the degradation of these resources. As a result, a country could cut its forests and deplete its fisheries, and this would show only as a positive gain in [gross clomestic product (GDP)] (a measure of current economic well-being) without registering the corresponcling decline in assets (wealth) that is the more appropriate measure of future economic wellbeing. Moreover, many ecosystem services (such as fresh water in aquifers and the use of the atmosphere as a sink for pollutants) are available freely to those who use them, and so again their degraclation is not reflected in standard economic measures.

When estimates of the economic losses associated with the depletion of natural assets are factored into measurements of the total wealth of nations, they significantly change the balance sheet of countries with economies significantly dependent on natural resources. For example, countries such as Ecuador, Ethiopia, Kazakhstan, Democratic Republic of Congo, Trinidad and Tobago, Uzbekistan, and Venezuela that had positive growth in net savings in 2001, reflecting a growth in the net wealth of the country, actually experienced a loss in net savings when depletion of natural resources (energy and forests) and estimated damages from carbon emissions (associated with contributions to climate change) were factored into the accounts.

While degradation of some services may sometimes be warranted to produce a greater gain in other services, often more degradation of ecosystem services takes place than is in society's interests because many of the services degraded are "public goods." Although people benefit from ecosystem services such as the regulation of air and water quality or the presence of an aesthetically pleasing landscape, there is no market for these services and no one person has an incentive to pay to maintain the good. And when an action results in the degradation of a service that harms other individuals, no market mechanism exists (nor, in many cases, could it exist) to ensure that the individuals harmed are compensated for the damages they suffer. 
Wealthy populations cannot be insulated from the degradation of ecosystem services. Agriculture, fisheries, and forestry once formed the bulk of national economies, and the control of natural resources dominated policy agendas. But while these natural resource industries are often still important, the relative economic and political significance of other industries in industrial countries has grown over the past century as a result of the ongoing transition from agricultural to industrial and service economies, urbanization, and the development of new technologies to increase the production of some services and provide substitutes for others. Nevertheless, the degradation of ecosystem services influences human well-being in industrial regions and among wealthy populations in developing countries in many ways:

- The physical, economic, or social impacts of ecosystem service degradation may cross boundaries.... For example, land degradation and associated dust storms or fires in one country can degrade air quality in other countries nearby.

- Degradation of ecosystem services exacerbates poverty in developing countries, which can affect neighboring industrial countries by slowing regional economic growth and contributing to the outbreak of conflicts or the migration of refugees.

- Changes in ecosystems that contribute to greenhouse gas emissions contribute to global climate changes that affect all countries.

- Many industries still depend directly on ecosystem services. The collapse of fisheries, for example, has harmed many communities in industrial countries. Prospects for the forest, agriculture, fishing, and ecotourism industries are all directly tied to ecosystem services, while other sectors such as insurance, banking, and health are strongly, if less directly, influenced by changes in ecosystem services.

- Wealthy populations of people are insulated from the harmful effects of some aspects of ecosystem degradation, but not all. For example, substitutes are typically not available when cultural services are lost.

- Even though the relative economic importance of agriculture, fisheries, and forestry is declining in industrial countries, the importance of other ecosystem services such as aesthetic enjoyment and recreational options is growing.

It is difficult to assess the implications of ecosystem changes and to manage ecosystems effectively because many of the effects are slow to become apparent, because they may be expressed primarily at some distance from where the ecosystem was changed, and because the costs and benefits of changes often accrue to different sets of stakeholders. Substantial inertia (delay in the response of a system to a disturbance) exists in ecological systems. As a result, long time lags often occur between a change in a driver and the time when the full consequences of that change become apparent. For example, phosphorus is accumulating in large quantities in many agricultural soils, threatening rivers, lakes, and coastal oceans with increased eutrophication. But it may take years or decades for the full impact of the phosphorus to become apparent through erosion and other processes. Similarly, it will take centuries for global temperatures to reach equilibrium with changed concentrations of greenhouse gases in the atmosphere and even more time for biological systems to respond to the changes in climate.

Moreover, some of the impacts of ecosystem changes may be experienced only at some distance from where the change occurred. For example, changes in upstream catchments affect water flow and water quality in downstream regions; similarly, the loss of an important fish nursery area in a coastal wetland may diminish fish catch some distance away. Both the inertia in ecological systems and the temporal and spatial separation of costs and benefits of ecosystem changes often result in situations where the individuals experiencing harm from ecosystem changes (future generations, say, or downstream landowners) are not the same as the individuals gaining the benefits. These temporal and spatial patterns make it extremely difficult to fully assess costs and benefits associated 
with ecosystem changes or to attribute costs and benefits to different stakeholders. Moreover, the institutional arrangements now in place to manage ecosystems are poorly designed to cope with these challenges.

\section{InCREASed Likelihood of Nonlinear (STEPPed) and Potentially Abrupt Changes IN ECOSYSTEMS}

... Changes in ecosystems generally take place gradually. Some changes are nonlinear, however: once a threshold is crossed, the system changes to a very different state. And these nonlinear changes are sometimes abrupt; they can also be large in magnitude and difficult, expensive, or impossible to reverse. Capabilities for predicting some nonlinear changes are improving, but for most ecosystems and for most potential nonlinear changes, while science can often warn of increased risks of change[,] it cannot predict the thresholds at which the change will be encountered. Examples of large magnitude nonlinear changes include:

- Disease emergence. If, on average, each infected person infects at least one other person, then an epidemic spreads, while if the infection is transferred on average to less than one person, the epidemic dies out. During the 1997-98 El Niño, excessive flooding caused cholera epidemics in Djibouti, Somalia, Kenya, Tanzania, and Mozambique. Warming of the African Great Lakes due to climate change may create conditions that increase the risk of cholera transmission in the surrounding countries.

- Eutrophication and hypoxia. Once a threshold of nutrient loading is achieved, changes in freshwater and coastal ecosystems can be abrupt and extensive, creating harmful algal blooms (including blooms of toxic species) and sometimes leading to the formation of oxygen-depleted zones, killing most animal life.

- Fisheries collapse. For example, the Atlantic cod stocks off the east coast of Newfoundland collapsed in 1992, forcing the closure of the fishery after hundreds of years of exploitation. Most important, depleted stocks may take years to recover, or not recover at all, even if harvesting is significantly reduced or eliminated entirely.

- Species introductions and losses. The introduction of the zebra mussel into aquatic systems in the United States, for instance, resulted in the extirpation of native clams in Lake St. Clair and annual costs of $\$ 100$ million to the power industry and other users.

- Regional climate change. Deforestation generally leads to decreased rainfall. Since forest existence crucially depends on rainfall, the relationship between forest loss and precipitation decrease can form a positive feedback, which, under certain conditions, can lead to a nonlinear change in forest cover.

The growing bushmeat trade poses particularly significant threats associated with nonlinear changes, in this case accelerating rates of change. Growth in the use and trade of bushmeat is placing increasing pressure on many species, especially in Africa and Asia. While the population size of harvested species may decline gradually with increasing harvest for some time, once the harvest exceeds sustainable levels, the rate of decline of populations of the harvested species will tend to accelerate. This could place them at risk of extinction and also reduce the food supply of people dependent on these resources in the longer term. At the same time, the bushmeat trade involves relatively high levels of interaction between humans and some relatively closely related wild animals that are eaten. Again, this increases the risk of a nonlinear change, in this case the emergence of new and serious pathogens. Given the speed and magnitude of international travel today, new pathogens could spread rapidly around the world.

The increased likelihood of these nonlinear changes stems from the loss of biodiversity and growing pressures from multiple direct drivers of ecosystem change. The loss of species and genetic diversity decreases the resilience of ecosystems, which is the level of disturbance that an 
ecosystem can undergo without crossing a threshold to a different structure or functioning. In addition, growing pressures from drivers such as overharvesting, climate change, invasive species, and nutrient loading push ecosystems toward thresholds that they might otherwise not encounter.

\section{Exacerbation of Poverty for Some Individuals and Groups of People and Contribution to Growing Inequities and Disparities Across Groups of People}

Despite the progress achieved in increasing the production and use of some ecosystem services, levels of poverty remain high, inequities are growing, and many people still do not have a sufficient supply of or access to ecosystem services.

- In 2001, 1.1 billion people survived on less than $\$ 1$ per day of income, with roughly $70 \%$ of them in rural areas where they are highly dependent on agriculture, grazing, and hunting for subsistence.

- Inequality in income and other measures of human wellbeing has increased over the past decade. A child born in sub-Saharan Africa is 20 times more likely to die before age 5 than a child born in an industrial country, and this disparity is higher than it was a decade ago. During the 199os, 21 countries experienced declines in their rankings in the Human Development Index (an aggregate measure of economic well-being, health, and education); 14 of them were in sub-Saharan Africa.

- Despite the growth in per capita food production in the past four decades, an estimated 852 million people were undernourished in 2000-2, up 37 million from the period 1997-99. South Asia and sub-Saharan Africa, the regions with the largest numbers of undernourished people, are also the regions where growth in per capita food production has lagged the most. Most notably, per capita food production has declined in sub-Saharan Africa.

- Some 1.1 billion people still lack access to improved water supply, and more than 2.6 billion lack access to improved sanitation. Water scarcity affects roughly $1-2$ billion people worldwide. Since 1960 , the ratio of water use to accessible supply has grown by $20 \%$ per decade.

The degradation of ecosystem services is harming many of the world's poorest people and is sometimes the principal factor causing poverty.

- Half the urban population in Africa, Asia, Latin America, and the Caribbean suffers from one or more diseases associated with inadequate water and sanitation. Worldwide, approximately 1.7 million people die annually as a result of inadequate water, sanitation, and hygiene.

- The declining state of capture fisheries is reducing an inexpensive source of protein in developing countries. Per capita fish consumption in developing countries, excluding China, declined between 1985 and 1997.

- Desertification affects the livelihoods of millions of people, including a large portion of the poor in drylands.

The pattern of "winners" and "losers" associated with ecosystem changes - and in particular the impact of ecosystem changes on poor people, women, and indigenous peoples has not been adequately taken into account in management decisions. Changes in ecosystems typically yield benefits for some people and exact costs on others who may either lose access to resources or livelihoods or be affected by externalities associated with the change. For several reasons, groups such as the poor, women, and indigenous communities have tended to be harmed by these changes.

- Many changes in ecosystem management have involved the privatization of what were formerly common pool resources. Individuals who depended on those resources (such as indigenous 
peoples, forest-dependent communities, and other groups relatively marginalized from political and economic sources of power) have often lost rights to the resources.

- Some of the people and places affected by changes in ecosystems and ecosystem services are highly vulnerable and poorly equipped to cope with the major changes in ecosystems that may occur. Highly vulnerable groups include those whose needs for ecosystem services already exceed the supply, such as people lacking adequate clean water supplies, and people living in areas with declining per capita agricultural production.

- Significant differences between the roles and rights of men and women in many societies lead to increased vulnerability of women to changes in ecosystem services.

- The reliance of the rural poor on ecosystem services is rarely measured and thus typically overlooked in national statistics and poverty assessments, resulting in inappropriate strategies that do not take into account the role of the environment in poverty reduction. For example, a recent study that synthesized data from 17 countries found that $22 \%$ of household income for rural communities in forested regions comes from sources typically not included in national statistics, such as harvesting wild food, fuelwood, fodder, medicinal plants, and timber. These activities generated a much higher proportion of poorer families' total income than of wealthy families', and this income was of particular significance in periods of both predictable and unpredictable shortfalls in other livelihood sources.

Development prospects in dryland regions of developing countries are especially dependent on actions to avoid the degradation of ecosystems and slow or reverse degradation where it is occurring. Dryland systems cover about $41 \%$ of Earth's land surface and more than 2 billion people inhabit them, more than 90\% of whom are in developing countries. Dryland ecosystems (encompassing both rural and urban regions of drylands) experienced the highest population growth rate in the 199 os of any of the systems examined in the [Millennium Assessment]... Although drylands are home to about one third of the human population, they have only $8 \%$ of the world's renewable water supply. Given the low and variable rainfall, high temperatures, low soil organic matter, high costs of delivering services such as electricity or piped water, and limited investment in infrastructure due to the low population density, people living in drylands face many challenges. They also tend to have the lowest levels of human well-being, including the lowest per capita GDP and the highest infant mortality rates.

The combination of high variability in environmental conditions and relatively high levels of poverty leads to situations where people can be highly vulnerable to changes in ecosystems, although the presence of these conditions has led to the development of very resilient land management strategies. Pressures on dryland ecosystems already exceed sustainable levels for some ecosystem services, such as soil formation and water supply, and are growing. Per capita water availability is currently only two thirds of the level required for minimum levels of human wellbeing. Approximately 10-20\% of the world's drylands are degraded (medium certainty) directly harming the people living in these areas and indirectly harming a larger population through bioplyysical impacts (dust storms, greenhouse gas emissions, and regional climate change) and through socioeconomic impacts (human migration and deepening poverty sometimes contributing to conflict and instability). Despite these tremendous challenges, people living in drylands and their land management systems have a proven resilience and the capability of preventing land degradation, although this can be either undermined or enhanced by public policies and development strategies.

\section{Finding \#3: [Ecosystem Prospects for the Next $5 \circ$ Years]}

... The most important direct drivers of change in ecosystems are habitat change (land use change and physical modification of rivers or water withdrawal from rivers), overexploitation, invasive alien 
species, pollution, and climate change. These direct drivers are often synergistic. For example, in some locations land use change can result in greater nutrient loading (if the land is converted to high-intensity agriculture), increased emissions of greenhouse gases (if forest is cleared), and increased numbers of invasive species (due to the disturbed habitat).

- Habitat transformation, particularly from conversion to agriculture: Under the MA scenarios, a further $10-20 \%$ of grassland and forestland is projected to be converted between 2000 and 2050 (primarily to agriculture). The projected land conversion is concentrated in low-income countries and dryland regions. Forest cover is projected to continue to increase within industrial countries.

- Overexploitation, especially overfishing: Over much of the world, the biomass of fish targeted in fisheries (including that of both the target species and those caught incidentally) has been reduced by $90 \%$ relative to levels prior to the onset of industrial fishing, and the fish being harvested are increasingly coming from the less valuable lower trophic levels as populations of higher trophic level species are depleted.... These pressures continue to grow in all the MA scenarios.

- Invasive alien species: The spread of invasive alien species and disease organisms continues to increase because of both deliberate translocations and accidental introductions related to growing trade and travel, with significant harmful consequences to native species and many ecosystem services.

- Pollution, particularly nutrient loading: Humans have already doubled the flow of reactive nitrogen on the continents, and some projections suggest that this may increase by roughly a further two thirds by 2050. Three out of four MA scenarios project that the global flux of nitrogen to coastal ecosystems will increase by a further $10-20 \%$ by 2030 (medium certainty), with almost all of this increase occurring in developing countries. Excessive flows of nitrogen contribute to eutrophication of freshwater and coastal marine ecosystems and acidification of freshwater and terrestrial ecosystems (with implications for biodiversity in these ecosystems). To some degree, nitrogen also plays a role in creation of ground-level ozone (which leads to loss of agricultural and forest productivity), destruction of ozone in the stratosphere (which leads to depletion of the ozone layer and increased UVB radiation on Earth, causing increased incidence of skin cancer), and climate change. The resulting health effects include the consequences of ozone pollution on asthma and respiratory function, increased allergies and asthma due to increased pollen production, the risk of blue-baby syndrome, increased risk of cancer and other chronic diseases from nitrates in drinking water, and increased risk of a variety of pulmonary and cardiac diseases from the production of fine particles in the atmosphere.

- Anthropogenic climate change: Observed recent changes in climate, especially warmer regional temperatures, have already had significant impacts on biodiversity and ecosystems, including causing changes in species distributions, population sizes, the timing of reproduction or migration events, and an increase in the frequency of pest and disease outbreaks. Many coral reefs have undergone major, although often partially reversible, bleaching episodes when local sea surface temperatures have increased during one month by $0.5^{-1} 1^{\circ}$ Celsius above the average of the hottest months.

By the end of the century, climate change and its impacts may be the dominant direct driver of biodiversity loss and changes in ecosystem services globally. The scenarios developed by the Intergovernmental Panel on Climate Change project an increase in global mean surface temperature of 2.0-6.4 ${ }^{\circ}$ Celsius above preindustrial levels by 2100 , increased incidence of floods and droughts, and a rise in sea level of an additional 8-88 centimeters between 1990 and 2100 . Harm to biodiversity will grow worldwide with increasing rates of change in climate and increasing 
absolute amounts of change. In contrast, some ecosystem services in some regions may initially be enhanced by projected changes in climate (such as increases in temperature or precipitation), and thus these regions may experience net benefits at low levels of climate change. As climate change becomes more severe, however, the harmful impacts on ecosystem services outweigh the benefits in most regions of the world. The balance of scientific evidence suggests that there will be a significant net harmful impact on ecosystem services worldwide if global mean surface temperature increases more than $2^{\circ}$ Celsius above preindustrial levels or at rates greater than $0.2^{\circ}$ Celsius per decade (medium certainty). There is a wide band of uncertainty in the amount of warming that would result from any stabilized greenhouse gas concentration, but based on IPCC projections[,] this would require an eventual $\mathrm{CO}_{2}$ stabilization level of less than 450 parts per million carbon dioxide (medium certainty).

The degradation of ecosystem services poses a significant barrier to the achievement of the Millennium Development Goals ${ }^{2}$ and the MDG targets for 2015. The eight Millennium Development Goals [MDGs] adopted by the United Nations in 2000 aim to improve human well-being by reducing poverty, hunger, child and maternal mortality, by ensuring education for all, by controlling and managing diseases, by tackling gender disparity, by ensuring environmental sustainability, and by pursuing global partnerships. Under each of the MDGs, countries have agreed to targets to be achieved by 2015. Many of the regions facing the greatest challenges in achieving these targets coincide with regions facing the greatest problems of ecosystem degradation. Although socioeconomic policy changes will play a primary role in achieving most of the MDGs, many of the targets (and goals) are unlikely to be achieved without significant improvement in management of ecosystems. The role of ecosystem changes in exacerbating poverty (Goal 1, Target 1) for some groups of people has been described already, and the goal of environmental sustainability, including access to safe drinking water (Goal 7, Targets 9, 10, and 11), cannot be achieved as long as most ecosystem services are being degraded. Progress toward three other MDGs is particularly dependent on sound ecosystem management...

\section{Finding \#4: [Reversing Ecosystem Degradation]}

An effective set of responses to ensure the sustainable management of ecosystems must address the indirect and drivers just described and must overcome barriers related to:

- Inappropriate institutional and governance arrangements, including the presence of corruption and weak systems of regulation and accountability.

- Market failures and the misalignment of economic incentives.

- Social and behavioral factors, including the lack of political and economic power of some groups (such as poor people, women, and indigenous peoples) that are particularly dependent on ecosystem services or harmed by their degradation.

- Underinvestment in the development and diffusion of technologies that could increase the efficiency of use of ecosystem services and could reduce the harmful impacts of various drivers of ecosystem change.

- Insufficient knowledge (as well as the poor use of existing knowledge) concerning ecosystem services and management, policy, technological, behavioral, and institutional responses that could enhance benefits from these services while conserving resources.

2 [In 2000, U.N. member states met to address the problem of extreme poverty throughout the world. The Millennial Development Goals they adopted, to be achieved by 2015 , include addressing environmental conditions as they relate to poverty. Halfway through the comnitment period, the United Nations issued a somewhat gloomy report on the progress being made towards achieving these goals. See Millennium Progress Report (2008). - Eds.] 
All these barriers are further compounded by weak human and institutional capacity related to the assessment and management of ecosystem services, underinvestment in the regulation and management of their use, lack of public awvareness, and lack of awareness among decision-makers of both the threats posed by the degradation of ecosystem services and the opportunities that more sustainable management of ecosystems could provide....

\section{INSTITUTIONS AND GOVERNANCE}

... Many existing institutions at both the global and the national level have the mandate to address the degradation of ecosystem services but face a variety of challenges in doing so related in part to the need for greater cooperation across sectors and the need for coordinated responses at multiple scales. However, since a number of the issues identified in this assessment are recent concerns and were not specifically taken into account in the design of today's institutions, changes in existing institutions and the development of new ones may sometimes be needed, particularly at the national scale.

In particular, existing national and global institutions are not well designed to deal with the management of common pool resources, a characteristic of many ecosystem services. Issues of ownership and access to resources, rights to participation in decision-making, and regulation of particular types of resource use or discharge of wastes can strongly influence the sustainability of ecosystem management and are fundamental determinants of who wins and loses from changes in ecosystems. Corruption, a major obstacle to effective management of ecosystems, also stems from weak systems of regulation and accountability.

Economic and financial interventions provide powerful instruments to regulate the use of ecosystem goods and services. Because many ecosystem services are not traded in markets, markets fail to provide appropriate signals that might otherwise contribute to the efficient allocation and sustainable use of the services. A wide range of opportunities exists to influence human behavior to address this challenge in the form of economic and financial instruments. However, market mechanisms and most economic instruments can only work effectively if supporting institutions are in place, and thus there is a need to build institutional capacity to enable more widespread use of these mechanisms.

Promising interventions include:

- Elimination of subsidies that promote excessive use of ecosystem services (and, where possible, transfer of these subsidies to payments for non-marketed ecosystem senvices). Government subsidies paid to the agricultural sectors of [Organisation of Economic Co-operation and Development (OECD)] countries between 2001 and 2003 averaged over $\$ 324$ billion annually, or one third the global value of agricultural products in 2000. A significant proportion of this total involved production subsidies that led to greater food production in industrial countries than the global market conditions warranted, promoted overuse of fertilizers and pesticides in those countries, and reduced the profitability of agriculture in developing countries. Many countries outside the OECD also have inappropriate input and production subsidies, and inappropriate subsidies are common in other sectors such as water, fisheries, and forestry. Although removal of perverse subsidies will produce net benefits, it will not be without costs. Compensatory mechanisms may be needed for poor people who are adversely affected by the removal of subsidies, and removal of agricultural subsidies within the OECD would need to be accompanied by actions designed to minimize adverse impacts on ecosystem services in developing countries.

- Greater use of economic instruments and market-based approaches in the management of ecosystem services. These include: 
- Taxes or user fees for activities with "external" costs (tradeoffs not accounted for in the market). Examples include taxes on excessive application of nutrients or ecotourism user fees.

- Creation of markets, including through cap-and-trade systems. One of the most rapidly growing markets related to ecosystem services is the carbon market. Approximately 64 million tons of carbon dioxide equivalent were exchanged through projects from January to May 2004, nearly as much as during all of 2003 . The value of carbon trades in 2003 was approximately $\$ 300$ million. About one quarter of the trades involved investment in ecosystem services (hydropower or biomass). It is speculated that this market may grow to \$10 billion to \$44 billion by 2010. The creation of a market in the form of a nutrient trading system may also be a low-cost way to reduce excessive nutrient loading in the United States.

- Payment for ecosystem services. For example, in 1996 Costa Rica established a nationwide system of conservation payments to induce landowners to provide ecosystem services. Under this program, Costa Rica brokers contracts between international and domestic "buyers" and local "sellers" of sequestered carbon, biodiversity, watershed services, and scenic beauty. Another innovative conservation financing mechanism is "biodiversity offsets," whereby developers pay for conservation activities as compensation for unavoidable harm that a project causes to biodiversity.

- Mechanisms to enable consumer preferences to be expressed through markets. For example, current certification schemes for sustainable fisheries and forest practices provide people with the opportunity to promote sustainability through their consumer choices.

\section{KNowledge Responses}

Effective management of ecosystems is constrained both by the lack of knowledge and information about different aspects of ecosystems and by the failure to use adequately the information that does exist in support of management decisions. In most regions, for example, relatively limited information exists about the status and economic value of most ecosystem services, and their depletion is rarely tracked in national economic accounts. Basic global data on the extent and trend in different types of ecosystems and land use are surprisingly scarce. Models used to project future environmental and economic conditions have limited capability of incorporating ecological "feedbacks," including nonlinear changes in ecosystems, as well as behavioral feedbacks such as learning that may take place through adaptive management of ecosystems. At the same time, decision-makers do not use all of the relevant information that is available. This is due in part to institutional failures that prevent existing policy-relevant scientific information from being made available to decision-makers and in part to the failure to incorporate other forms of knowledge and information (such as traditional knowledge and practitioners' knowledge) that are often of considerable value for ecosystem management.

Promising interventions include:

- Incorporation of nonmarket values of ecosystems in resource management and investment decisions. Most resource management and investment decisions are strongly influenced by considerations of the monetary costs and benefits of alternative policy choices. Decisions can be improved if they are informed by the total economic value of alternative management options and involve deliberative mechanisms that bring to bear noneconomic considerations as well....

- Enhancing and sustaining human and institutional capacity for assessing the consequences of ecosystem change for human well-being and acting on such assessments. Greater technical capacity is needed for agriculture, forest, and fisheries management. But the capacity that exists 
for these sectors, as limited as it is in many countries, is still vastly greater than the capacity for effective management of other ecosystem services.

\section{Questions and Discussion}

1. What is the underlying rationale for environmental protection? Is it concern for nature or concern for humans? Can the two be separated? See KLAus Bosselmann, When Two Worlds Collide: Society And Ecology (1995); Christopher D. Stone, The Gnat Is Older Than Man: Global Environment and the Human Agenda (1993); Roderick Frazier Nash, The Rights of Nature: A History of Environmental Ethics (1989).

2. To the extent environmental protection is about human well-being, does the concern expressed extend to humans presently alive or also to future generations? Why should present generations care about the future? If they do, how should the needs and interests of the future be determined and protected in the present? See the discussion of intergenerational equity, infra at section 5 (a).

3. How can common-pool resources be managed? Garrett Hardin described a "tragedy of the commons" in 1968, positing a common pasture in which everyone in a village has unlimited grazing rights for cattle. It is to each person's advantage in the short run to maximize the grazing of her or his own cattle. Over time, the pasture is destroyed through overgrazing. Garrett Hardin, Tragedy of the Commons, 168 SCIENCE 243 (Dec. 13, 1968). The crashing fisheries in oceans around the world demonstrate the continued validity of Hardin's analysis. What legal solutions can address the tragedy of the commons in a state or in international commons areas like the high seas? Do rights have any role to play?

4. Are those persons and states who contribute the most to environmental degradation bearing their fair share of the resulting burdens? If not, should environmental law try to allocate more equitably the benefits and burdens of human activities that impact the environment?

5. To what extent does the Millennium Assessment suggest the need for environmental law as opposed to education, ethics, or other approaches to prevent further loss of ecosystem services?

6. What is the role of economic analysis and accounting revealed by the MA? Does GDP take into account ecological services? Can it? How can the value of honeybees in pollinating plants be measured? See, e.g., Nature's Services: Societal Dependence on Natural Ecosystems (Gretchen C. Daily ed., 1997); Dana Clark \& David Downes, Wiiat Price Biodiversity? (1995); Robert Costanza Et al., AN Introduction to Ecological Economics (1997); Herman E. Daly \& Joshua Farley, Ecological Economics: Principles and Applications (2003); Michael Common \& Sigrid Stagl, Ecological Economics: AN INTRODUCTION (2005).

\section{Approaches to Environmental Protection}

Deep and growing concern for the environment and the ability of future generations to meet their needs has been a driver of profound changes in the law (both municipal and international) over the past fifty years. Today, a vast system of public environmental law in many countries forms one of the linchpins of the modern regulatory state. Alongside this public law edifice, other complementary legal and policy mechanisms promote environmental protection. In general, laws concerning the environment can be grouped into four broad categories: private law, especially tort and property law; public regulation (including criminal law); market mechanisms; and constitutional or human rights law. As you study 